\title{
Comparison between noninvasive and conventional skin closure methods in off-pump coronary artery bypass grafting using bilateral internal thoracic artery
}

\author{
Heemoon Lee, Sang Yoon Yeom, Hee Jung Kim, Jae Suk Yoo, Dong Jin Kim, Kwang Ree Cho \\ Departments of Thoracic and Cardiovascular Surgery, Sejong General Hospital, Bucheon-si, Gyeonggi-do, Korea \\ Contributions: (I) Conception and design: KR Cho; (II) Administrative support: KR Cho, JS Yoo, DJ Kim; (III) Provision of study materials or \\ patients: KR Cho, SY Yeom, HJ Kim; (IV) Collection and assembly of data: KR Cho, H Lee, HJ Kim; (V) Data analysis and interpretation: KR Cho, \\ H Lee, SY Yeom; (VI) Manuscript writing: All authors; (VII) Final approval of manuscript: All authors. \\ Correspondence to: Kwang Ree Cho, MD, PhD. Departments of Thoracic and Cardiovascular Surgery, Sejong General Hospital, 28 Hohyeon-ro \\ 489beon-gil, Bucheon-si, Gyeonggi-do 14754, Korea. Email: ckrym@hanmail.net.
}

\begin{abstract}
Background: Sternal wound complications could increase the hospital cost while decreasing the satisfaction of surgery. Furthermore, it can potentially also lead to life-threatening mediastinitis especially after coronary artery bypass grafting using bilateral internal thoracic artery (BITA). Skill levels of suture technique vary among surgeons and may contribute to an increased wound complication rate. Thus, standardization of surgical wound closure could potentially decrease the surgeon factor. The aim of the study is to compare the wound complication rate between non-invasive surgical skin closure devices (zip surgical skin closure device, Zipline Medical, Campbell, CA, USA) and conventional suture closure.

Methods: Three hundred seventy-nine patients who underwent off-pump coronary artery bypass grafting (OPCAB) using BITAs at our institution between 2016 and 2018 were included in this study. Patients were divided into two groups; the Zipline group (zip-group, $\mathrm{N}=100$ ), and conventional group (con-group, N=279). Following propensity score matching, 95 con-group patients were matched to 169 zip-group patients.

Results: The average age and history of cancer were significantly higher in the zip-group $(\mathrm{P}=0.021$ and $\mathrm{P}=0.023$, respectively). However, after propensity score matching, no differences were observed in the demographic data between the groups. In total patients (unmatched), although there was no significant difference in the incidence of deep sternal wound infection (DSWI) between the two groups (zip vs. con, $0 \%$ vs. $1.1 \%, \mathrm{P}=0.569)$, the incidence of post-operative superficial sternal wound infection (SSWI) or dehiscence was significantly higher in the con-group than in the zip-group $(1.0 \%$ vs. $7.9 \%, \mathrm{P}=0.013)$. The results were consistent in the matched patients. (DSWI: $0 \%$ vs. 0.6\%, P>0.999; SSWI or dehiscence: $1.1 \%$ vs. $7.1 \%$, $\mathrm{P}=0.036)$. Multivariable analysis revealed use of the zip surgical skin closure device showed a preventive effect against wound complications [odds ratio (OR): 0.128, 95\% confidence interval (CI): 0.017-0.976, $\mathrm{P}=0.029$ ].

Conclusions: Zip surgical skin closure devices could decrease superficial wound complication rates compared to conventional suture techniques in OPCAB using BITAs.
\end{abstract}

Keywords: Wound closure techniques; surgical wound infection; surgical wound dehiscence

Submitted Apr 17, 2019. Accepted for publication Aug 06, 2019.

doi: $10.21037 /$ jtd.2019.08.87

View this article at: http://dx.doi.org/10.21037/jtd.2019.08.87

\section{Introduction}

Sternal wound complications can increase hospitalization costs and decrease patients' surgical outcome satisfaction.
It can also lead to life-threatening mediastinitis, especially after coronary artery bypass grafting performed using bilateral internal thoracic artery (BITA) (1). A suitable 


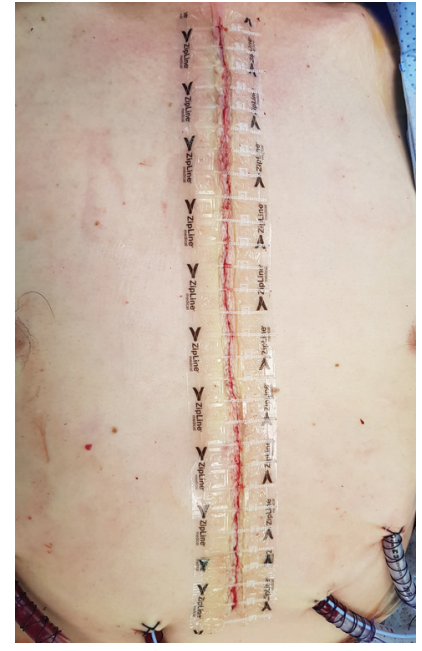

Figure 1 The zip surgical skin closure device.

surgical closure technique is one of the several key factors associated with appropriate wound healing $(2,3)$.

The objectives of wound closures are to achieve a safe and effective healing with aesthetically pleasing results. Suture and stapler closure methods are most commonly used for skin closures. However, suture closure is timeconsuming and requires a high degree of skill. On the other hand, the stapler method can be performed quickly and in less time, but it can also reduce patient satisfaction due to a "railroad track" mark at the site of the wound $(4,5)$. The zip surgical skin closure device (Zipline Medical, Campbell, CA, USA) is a novel and non-invasive skin closure system which provides an alternative to the suture- or staplerbased closures. It facilitates wound healing by protecting the wound from undesirable shear and axial forces. It also provides dynamic compression of the wound during axial distension (6). Additionally, it can be easily performed to promote the standardization of wound closure methods.

\section{Methods}

\section{Study population}

We retrospectively reviewed medical data recorded between January 2016 and February 2018 for 379 patients, who had undergone elective isolated off-pump coronary artery bypass grafting $(\mathrm{OPCAB})$ performed using BITA, at our institution. The mean age was $64.5 \pm 9.4$ years. There were 101 (26.6\%) female patients. The mean body weight was $65.4 \pm 10.1 \mathrm{~kg}$. The mean body mass index (BMI) was $24.8 \pm 2.8 \mathrm{~kg} / \mathrm{m}^{2}$, and the proportion of obesity was $44.1 \%$. Diabetes mellitus
(DM) was observed in 193 (50.9\%) patients, while chronic kidney disease (CKD) was observed in 54 (14.2\%) patients. Chronic obstructive pulmonary disease (COPD) was diagnosed in $15(4.0 \%)$ patients. The mean left ventricular ejection fraction (LVEF) was recorded to be $51.3 \pm 41.1 \%$. The patients were then divided into two groups. Individuals in the zip-group $(\mathrm{N}=100)$ had undergone skin closure with the zip skin closure device. Individuals in the con-group $(\mathrm{N}=279)$ had undergone skin closure with a conventional skin closure technique. The study protocol was approved by the Sejong General Hospital Institutional Review Board (IRB No. 2018-0811, approval date. 12-12-2018).

\section{Operative procedures}

All patients underwent OPCAB via standard median sternotomy with skeletonized BITA. Composite Y or I grafts were constructed after harvesting In most cases, the in situ left internal thoracic artery was anastomosed to the left anterior descending artery, otherwise the right internal thoracic artery was used. The remaining left circumflex artery or territories were revascularized with a sequential anastomosis technique.

An approximation of the sternum was performed by means of a standard manner using steel wires. The fascia and the subcutaneous layers were then closed with 1-0 and 3-0 Vicryl (Ethicon, Cincinnati, OH, USA) sutures, respectively. In the con-group, skin closure was performed using the subcuticular continuous suture closure technique with 4-0 Vicryl sutures in most cases and the stapler closure in some cases. In the zip-group, skin closure was performed using zip surgical skin closure device (Figure 1). Initially, we performed a conventional suture closure technique. And then, the zip surgical skin closure device was introduced and has been substituted for the conventional skin closure technique since July 2017. Seven surgeons performed wound closures in the con-group and 5 surgeons performed wound closure in the zip-group.

In the zip-group, removal of the device was performed at the $2^{\text {nd }}$ follow-up visit postoperatively. The mean length of the device maintenance period was $38.9 \pm 8.4$ days.

\section{Follow-up}

Hospital records were reviewed retrospectively. The primary endpoint was the incidence of wound dehiscence or occurrence of infection at the site of sternotomy incision. The extent of involvement (superficial and deep) was 
categorized according to previous guidelines (7). Superficial sternal wound infection (SSWI) included infection of the skin, subcutaneous tissue, or muscle present above the pectoralis fascia. Deep sternal wound infection (DSWI) was defined as an infection related to the tissue beneath the pectoralis fascia, and involved an infection of the sternum and mediastinal space.

\section{Statistical analysis}

Categorical variables were presented as numbers and percentages; continuous variables were presented as means and standard deviations. The inter-group differences were assessed using the $t$-test and Chi-square test. Univariable and multivariable logistic regression was performed to assess the independent risk factors for wound complications. The variables considered included age, sex, obesity (BMI $\geq 25 \mathrm{~kg} / \mathrm{m}^{2}$ ), hypertension (HTN), DM, insulin dependent diabetes mellitus (IDDM), non-insulin dependent diabetes mellitus (NIDDM), stroke, carotid artery stenosis, peripheral artery occlusive disease (PAOD), abdominal aortic aneurysm (AAA), chronic renal failure (CRF), CKD, COPD, percutaneous transluminal coronary angioplasty (PTCA), cancer, steroid usage, LVEF of $\leq 35 \%$, unstable angina, stable angina, non-ST elevation myocardial infarction (NSTEMI), ST elevation myocardial infarction (STEMI), triple vessel disease, and left main disease. Variables with $\mathrm{P}$ values $<0.2$ in the univariable analysis were included in the multivariable logistic regression model. $\mathrm{P}$ values $<0.05$ were considered statistically significant.

Propensity score matching was performed to minimize the differences in baseline characteristics between the groups. The propensity score was obtained by multiple logistic regression, based on the following preoperative baseline characteristics, age, sex, BMI, HTN, IDDM, NIDDM, stroke, carotid artery stenosis, PAOD, AAA, CRF, COPD, history of percutaneous transcatheter coronary angioplasty, history of cancer, LVEF of $\leq 35 \%$, unstable angina, stable angina, NSTEMI, STEMI, triple vessel disease, and left main disease. To prevent data loss during matching, we used the 1:n propensity matching method. A total of 95 con-group patients were matched to 169 zipgroup patients, by use of nearest-neighbor matching without replacement, and a matching tolerance (caliper) of 0.25 . The stratified $t$-test and Chi-square test were performed after matching. Statistical analysis was carried out using SPSS version 21.0 (SPSS, Chicago, IL, USA), and R 3.5.1 (R Foundation for Statistical Computing, Vienna, Austria).

\section{Results}

Table 1 describes the baseline characteristics of the patients. Patients of the zip-group were older (zip-group vs. congroup, $66 \pm 9.8$ vs. $63 \pm 9.2$ years, $\mathrm{P}=0.021)$ and had a higher occurring history of cancer $(10.0 \%$ vs. $3.9 \%, \mathrm{P}=0.023)$. However, the prevalence of DM $(50.0 \%$ vs. $51.3 \%$, $\mathrm{P}=0.830$ ), severe left ventricular dysfunction ( $\mathrm{LVEF}$ $\leq 35 \%)(17.0 \%$ vs. $17.7 \%, \mathrm{P}=0.876)$, COPD (2.0\% vs. $4.7 \%, \mathrm{P}=0.371)$, and obesity $\left(\mathrm{BMI} \geq 25 \mathrm{~kg} / \mathrm{m}^{2}\right),(45.0 \% v s$. $43.7 \%, \mathrm{P}=0.826$ ) was similar between the two groups. After propensity score matching, no differences in demographic data were observed between the groups (Table 1).

There were 4 in-hospital deaths (1.4\%) in the con-group and no in-hospital deaths in the zip-group in total patients $(\mathrm{P}=0.577)$. Early postoperative mortality or morbidities were not significantly different between the two groups in both total and matched patients (Table 2).

In total patients, the incidence of total wound complications was significantly higher in the con-group compared to the zip-group (25, 9.0\% in the con-group; 1 , $1.0 \%$ in the zip-group, $\mathrm{P}=0.005$, Figure 2). Among these cases, the incidence of SSWI or dehiscence was significantly higher in the con-group $(21,7.5 \%$ in the con-group; 1 , $1.0 \%$ in the zip-group, $\mathrm{P}=0.013$, Figure 3). However, the incidence of DSWI was not significantly different between the two groups $(3,1.1 \%$ in the con-group; $0,0 \%$ in zipgroup, $\mathrm{P}=0.569$, Figure 4).

The results were consistent in the matched patients. The incidence of total wound complications was also significantly higher in the con-group $(13,7.7 \%$ in the congroup; $1,1.1 \%$ in the zip-group, $\mathrm{P}=0.021$, Figure 2$)$. The incidence of SSWI or dehiscence was significantly higher in the con-group $(12,7.1 \%$ in the con-group; $1,1.1 \%$ in the zip-group, $\mathrm{P}=0.036$, Figure 3). However, the incidence of DSWI did not differ significantly between the two groups (1, $0.6 \%$ in the con-group; $0,0 \%$ in the zip-group, $\mathrm{P}>0.999$, Figure 4).

Table 3 presents the results of the univariable and multivariable logistic regression analyses for the assessment of risk factors for total wound complications. Multivariable analysis revealed diabetes [odds ratio (OR): 3.073, 95\% confidence interval (CI): 1.158-8.156, $\mathrm{P}=0.024]$ and $\mathrm{CRF}$ (OR: 4.738, 95\% CI: $1.396-16.083, \mathrm{P}=0.013$ ) to be the risk factors for wound complications. Use of the zip surgical skin closure device showed a preventive effect against wound complications (OR: 0.128, 95\% CI: 0.017-0.976, $\mathrm{P}=0.029$ ). 
Table 1 Baseline characteristics

\begin{tabular}{|c|c|c|c|c|c|c|c|c|}
\hline Variables & \multicolumn{4}{|c|}{ Total patients } & \multicolumn{4}{|c|}{ Propensity score matched patients } \\
\hline Age, years & $66 \pm 9.8$ & $63 \pm 9.2$ & 0.021 & 0.321 & $66 \pm 9.8$ & $66 \pm 9.0$ & 0.983 & 0.003 \\
\hline Sex, female, n (\%) & $32(32.0)$ & $69(24.7)$ & 0.158 & 0.145 & $30(31.6)$ & $47(27.8)$ & 0.539 & 0.081 \\
\hline $\mathrm{BMI}, \mathrm{kg} / \mathrm{m}^{2}$ & $24.6 \pm 2.7$ & $24.8 \pm 2.9$ & 0.526 & 0.070 & $24.6 \pm 2.7$ & $24.5 \pm 3.0$ & 0.954 & 0.007 \\
\hline HTN, n (\%) & $53(53.0)$ & $161(57.7)$ & 0.415 & 0.105 & $51(53.0)$ & $96(56.8)$ & 0.627 & 0.064 \\
\hline $\mathrm{DM}, \mathrm{n}(\%)$ & $50(50.0)$ & $143(51.3)$ & 0.830 & 0.028 & $47(49.5)$ & $88(52.1)$ & 0.687 & 0.053 \\
\hline IDDM, n (\%) & $12(12.0)$ & $27(9.7)$ & 0.643 & 0.048 & $11(11.6)$ & $23(13.6)$ & 0.634 & 0.063 \\
\hline NIDDM, n (\%) & $38(38.0)$ & $116(41.6)$ & 0.613 & 0.052 & $36(37.9)$ & $65(38.4)$ & 0.934 & 0.011 \\
\hline PAOD, n (\%) & $15(15.0)$ & $34(12.2)$ & 0.472 & 0.074 & $14(14.7)$ & $29(17.2)$ & 0.666 & 0.058 \\
\hline AAA, n (\%) & $4(4.0)$ & $5(1.8)$ & 0.251 & 0.118 & $2(2.1)$ & $5(3.0)$ & 0.639 & 0.066 \\
\hline CKD, n (\%) & $9(9.0)$ & $45(16.1)$ & 0.080 & 0.181 & $9(9.5)$ & $24(14.2)$ & 0.261 & 0.147 \\
\hline CRF, n (\%) ${ }^{a}$ & $3(3.0)$ & $15(5.4)$ & 0.422 & 0.083 & $3(3.2)$ & $5(3.0)$ & $>0.999$ & $<0.001$ \\
\hline COPD, n (\%) & $2(2.0)$ & $13(4.7)$ & 0.371 & 0.092 & $2(2.1)$ & $4(2.4)$ & 0.787 & 0.035 \\
\hline PTCA, n (\%) & $22(22.0)$ & $57(20.4)$ & 0.740 & 0.034 & $19(20.0)$ & 33 (19.5) & 0.921 & 0.013 \\
\hline Cancer, n (\%) & $10(10.0)$ & $11(3.9)$ & 0.023 & 0.235 & $6(6.3)$ & $13(7.7)$ & 0.762 & 0.042 \\
\hline Steroid use, n (\%) & $1(1.0)$ & $11(3.9)$ & 0.196 & 0.133 & $1(1.1)$ & $6(3.6)$ & 0.215 & 0.174 \\
\hline Triple vessel disease, $\mathrm{n}(\%)$ & $79(79.0)$ & $216(77.4)$ & 0.744 & 0.034 & $75(78.9)$ & $131(77.5)$ & 0.771 & 0.038 \\
\hline Left main disease, $\mathrm{n}(\%)$ & $28(28.0)$ & $83(29.7)$ & 0.857 & 0.019 & $27(28.4)$ & $53(31.4)$ & 0.599 & 0.069 \\
\hline
\end{tabular}

a, CRF patients under dialysis. SMD, standardized mean difference; BMI, body mass index; HTN, hypertension; DM, diabetes mellitus; IDDM, insulin dependent diabetes mellitus; NIDDM, non-insulin dependent diabetes mellitus; PAOD, peripheral artery occlusive disease; AAA, abdominal aortic aneurysm; CKD, chronic kidney disease; CRF, chronic renal failure; COPD, chronic obstructive pulmonary disease; PTCA, percutaneous transluminal coronary angioplasty; LVEF, left ventricular ejection fraction; NSTEMI, non-ST elevation myocardial infarction; STEMI, ST elevation myocardial infarction.

\section{Discussion}

Sternal wound complications can increase hospitalization costs, while they can decrease patient surgery outcome satisfaction. Additionally, they can also lead to lifethreatening mediastinitis, especially after OPCAB performed using BITA. Although skeletonization of
BITA suggested a decrease in the rate of sternal wound complications $(8,9)$, the use of BITA has been increased the risks of sternal wound complication $(1,10,11)$.

The zip surgical skin closure device is a novel, noninvasive skin closure system that provides an alternative to conventional suture or stapler closure methods. Favorable 
Table 2 Postoperative outcomes

\begin{tabular}{|c|c|c|c|c|c|c|}
\hline Variables & \multicolumn{3}{|c|}{ Total patients } & \multicolumn{3}{|c|}{ Propensity score matched patients } \\
\hline Atrial fibrillation, n (\%) & $28(28.0)$ & $54(19.4)$ & 0.072 & $25(26.3)$ & $36(21.3)$ & 0.338 \\
\hline PMI, n (\%) & $1(1.0)$ & $1(0.4)$ & 0.459 & $1(1.1)$ & $1(0.5)$ & 0.617 \\
\hline Post stroke, n (\%) & $0(0.0)$ & $8(2.9)$ & 0.117 & $0(0.0)$ & $5(3.0)$ & 0.105 \\
\hline LCOS, n (\%) & $0(0.0)$ & $1(0.4)$ & $>0.999$ & $0(0.0)$ & $0(0.0)$ & NA \\
\hline Respiratory complications, n (\%) & $2(2.0)$ & $11(3.9)$ & 0.527 & $2(2.1)$ & $6(3.6)$ & 0.487 \\
\hline Bleeding reoperation, $\mathrm{n}(\%)$ & $0(0.0)$ & $0(0.0)$ & NA & $0(0.0)$ & $0(0.0)$ & NA \\
\hline In-hospital mortality, n (\%) & $0(0.0)$ & $4(1.4)$ & 0.577 & $0(0.0)$ & $3(1.8)$ & 0.308 \\
\hline
\end{tabular}

NA, not applicable; PMI, perioperative myocardial infarction; AKI, acute kidney injury; LCOS, low cardiac output syndrome.
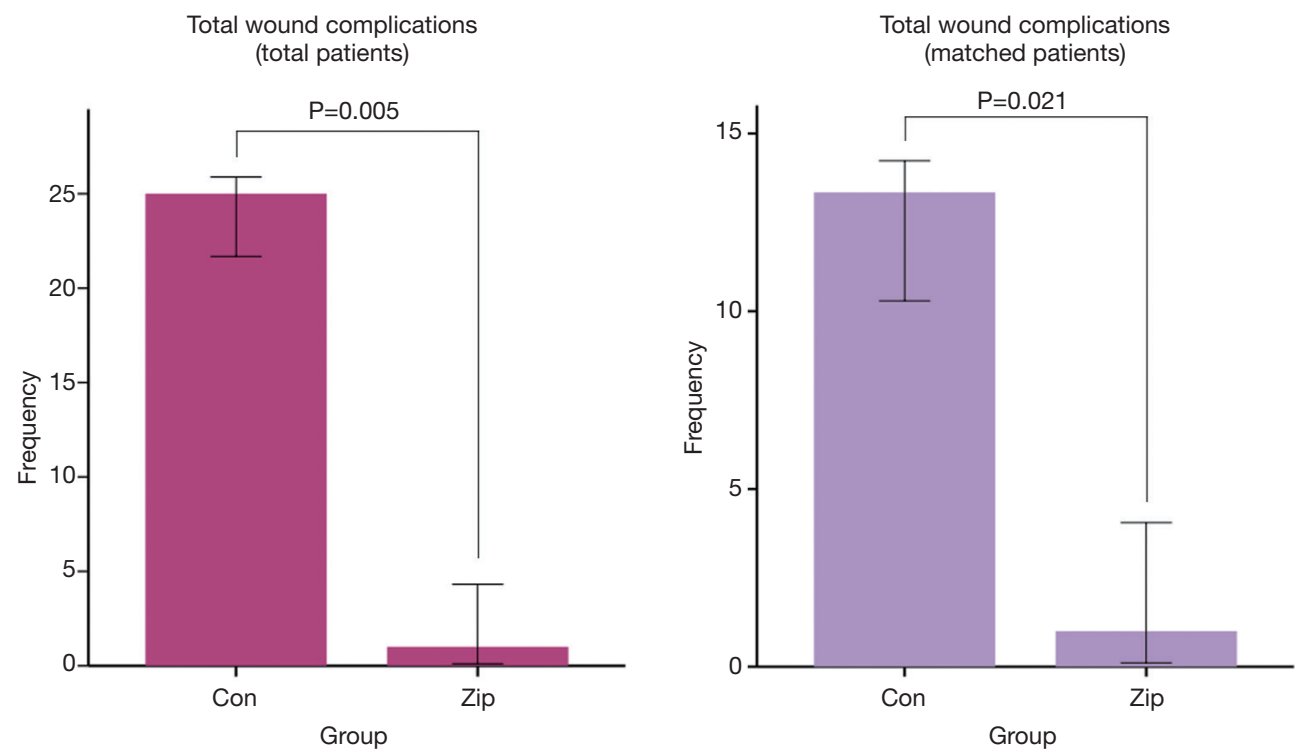

Figure 2 A comparison of the incidence of total sternal wound complications between the con-group and the zip-group, before and after matching.

results from the zip surgical skin closure device have been reported in other types of surgeries as well $(12,13)$. Furthermore, the use of the zip surgical skin closure device and favorable results has also been reported for cardiac surgery. Tanaka et al. reported a prospective randomized study including 214 patients who had undergone congenital heart operation (136 primary operations, 78 reoperations) to compare the zip surgical skin closure device $(\mathrm{N}=113)$ with the subcuticular sutures $(\mathrm{N}=101)$. They showed that although the surgical site infection was similar between the groups, Vancouver scar scale and skin closure time was shorter in the zip-group (14). However, their study included patients of congenital cardiac surgery only.

Our study demonstrated that the zip surgical skin closure device can be a feasible alternative to conventional skin closure methods using propensity score matching analysis, even in patients who have undergone OPCAB performed using BITA; these patients are regarded as high- 
SSWI or dehiscence (total patients)

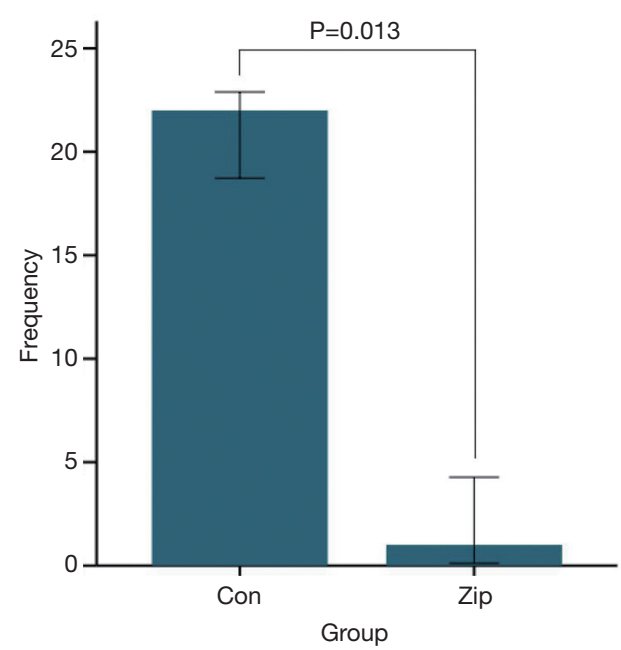

SSWI or dehiscence (matched patients)

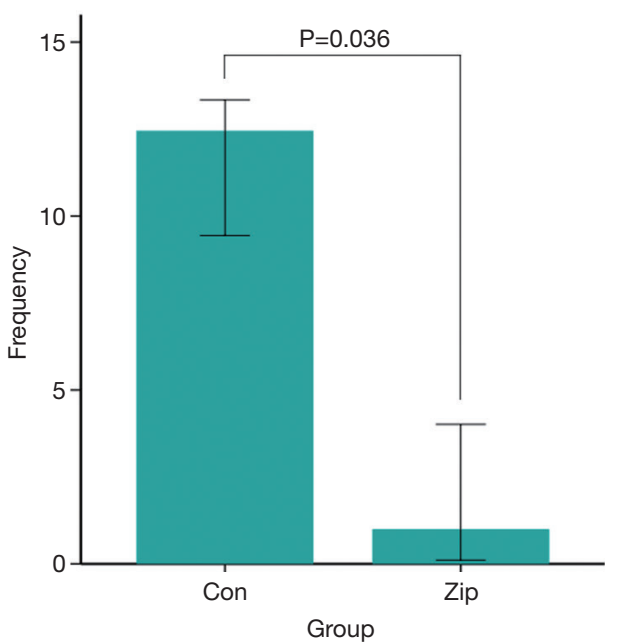

Figure 3 A comparison of the incidence of SSWI or dehiscence between the con-group and the zip-group, before and after matching. SSWI, superficial sternal wound infection.
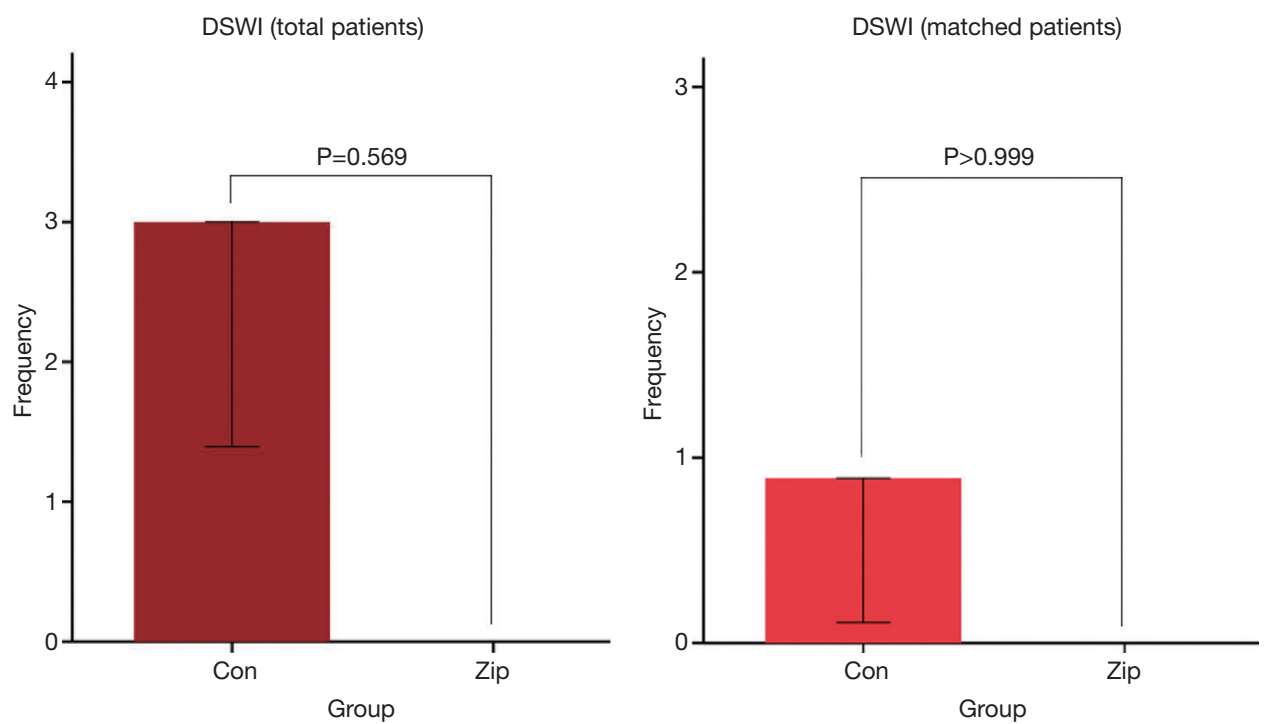

Figure 4 A comparison of the incidence of DSWI between the con-group and the zip-group, before and after matching. DSWI, deep sternal wound infection.

risk for sternal wound complications. The zip surgical skin closure device significantly decreased the occurrence of total wound complications as compared to conventional suture techniques; it especially decreased superficial wound complications. Although the incidence of DSWI did not differ between the two groups, there was no event in the zip-group, while three such events were recorded in the con-group. The multivariable analysis also revealed that the use of the zip surgical skin closure device acted as a protective factor against wound complications.

The zip surgical skin closure device has several advantages for wound healing. Firstly, it provides better cosmetically pleasing results without leaving the railroad track mark or stitch scar at the site of the wound. Secondly, it facilitates wound healing by protecting the wound from undesirable shear and axial forces. It also provides dynamic 
Table 3 Risk factor analyses for total wound complications

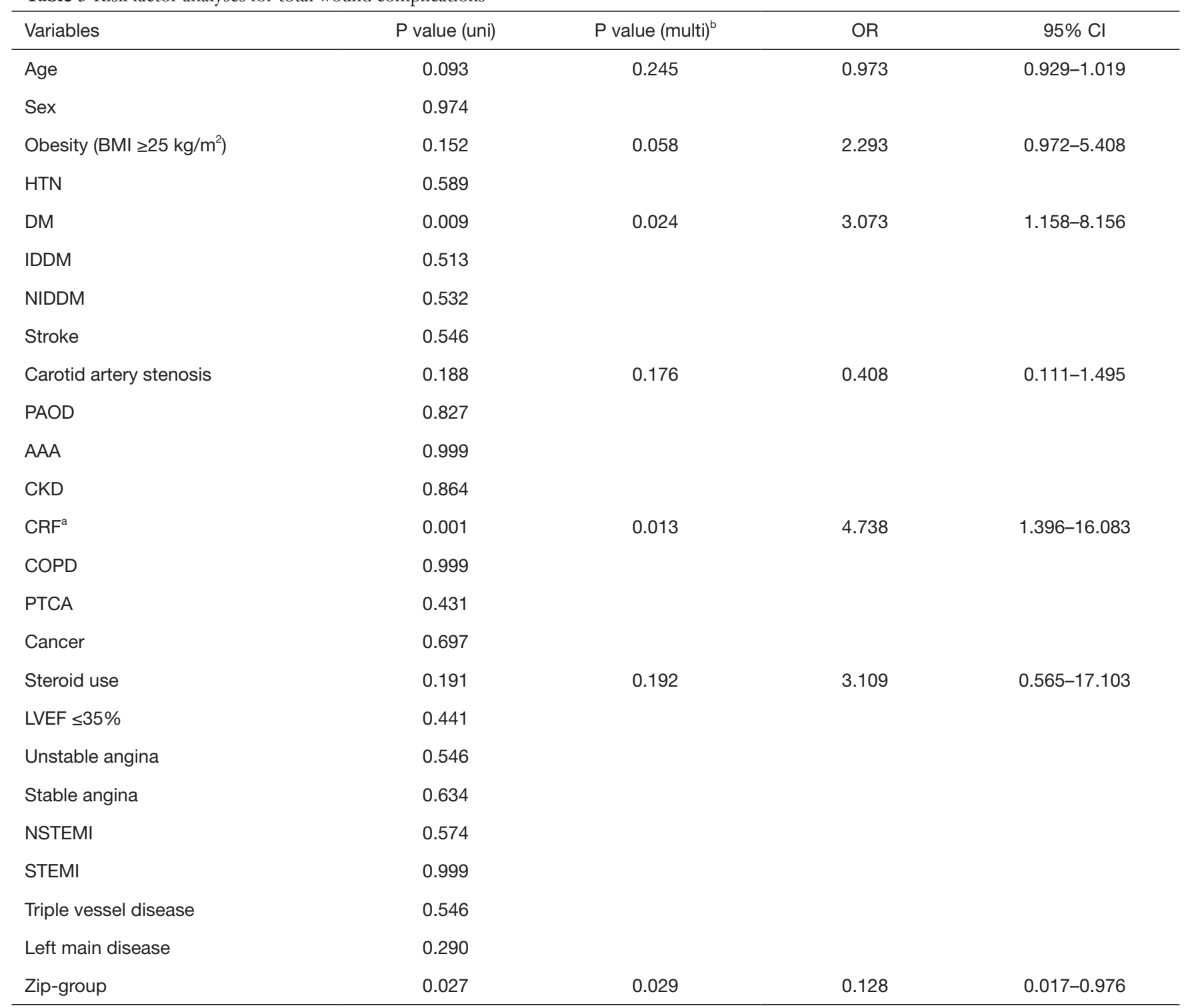

a, CRF patients under dialysis; ${ }^{b}$, variables entered for multivariable analysis were age, obesity (BMl $\left.\geq 25 \mathrm{~kg} / \mathrm{m}^{2}\right)$, carotid artery stenosis, CRF, steroid use, zip-group. BMI, body mass index; HTN, hypertension; DM, diabetes mellitus; IDDM, insulin dependent diabetes mellitus; NIDDM, non-insulin dependent diabetes mellitus; PAOD, peripheral artery occlusive disease; AAA, abdominal aortic aneurysm; CKD, chronic kidney disease; CRF, chronic renal failure; COPD, chronic obstructive pulmonary disease; PTCA, percutaneous transluminal coronary angioplasty; LVEF, left ventricular ejection fraction; NSTEMI, non-ST elevation myocardial infarction; STEMI, ST elevation myocardial infarction; OR, odds ratio; $\mathrm{Cl}$, confidence interval.

compression of the wound during axial distension. Finally, it can be applied easily and rapidly. The tension of the device can be adjusted easily by adapting the strap-rock system; the adjustment can be made multiple times based on the extent of the edema or wound healing after the operation $(6,14)$.

While several factors are associated with wound healing, appropriate surgical closure technique is one of the key factors for wound healing (2,3). In our study, 7 surgeons performed wound closures in the con-group and 5 surgeons performed wound closures in the zip-group. Suture closure requires a high degree of skill to be performed appropriately, and thus, technical variation can occur according to each surgeon's capability. On the other hand, the zip surgical skin closure device can be applied easily without advanced 
surgical skills, which decreases the chances of technical variation by each surgeon and promotes standardization of wound closure. Our study showed that the zip surgical skin closure device significantly decreases wound complication rate, especially for superficial wound complications, compared to the conventional suturing techniques; this was observed even in multivariable analysis and propensity score matching analysis. Our results imply that standardization of surgical wound closure methods might decrease the technical variation in suturing by different surgeons, and thus, contribute to decreasing wound complication rate.

Multivariable analysis showed that the use of the zip surgical skin closure device is the protective factor against wound complications. Besides, diabetes and CRF were also revealed to be risk factors for wound complications as suggested by previous reports $(3,15)$. In addition to the application of the zip surgical skin closure device, appropriate glucose control (16) and proper management with multidisciplinary approaches, including those for dialysis, control of electrolytes, and acid-base imbalance, uremia, edema, and inflammatory toxins (15) are necessary for appropriate wound healing in these high-risk patients.

In previous reports, the zip surgical skin closure device was removed after 7-14 days postoperatively (12-14). In our study, the mean length of device maintenance was $38.9 \pm 8.4$ days. We removed the device at the $2^{\text {nd }}$ follow-up visit postoperatively. Although the length of the period of device maintenance in our study was longer than previous studies, we tried to maintain it until wound healing was ensured. Because the zip surgical skin closure device does not leave any skin contracture or skin marks as can be observed with stapler or suture closure methods, it can be maintained for more than 14 days without any problems. A low rate of skin irritation, such as blister formation, may facilitate long-term maintenance as well (13).

Our study has several limitations. Firstly, this is a retrospective, non-randomized study that was performed at a single institution. Therefore, it may have been influenced by a selection bias. Therefore, we performed propensity matching to compensate for the potential bias in patient selection. However, an unidentified confounding bias may influence the results. Secondly, the time period of the application of the two different techniques was not identical. We initially performed the conventional suture closure technique at our institute, while the zip surgical skin closure device was introduced later; it was mainly used after July 2017. Finally, the selection of the two different closure techniques was determined by the surgeon as per their preference. Individual experience, anatomical factors, and the surgical risk for the patient may have influenced this decision. A prospective multicenter study with a larger number of patients may be necessary.

\section{Conclusions}

The zip skin closure device can facilitate standardization of surgical wound closure and decrease superficial wound complication rates in patients who have undergone $\mathrm{OPCAB}$ using BITA. A randomized controlled study with a larger population would be required to confirm the results of this study.

\section{Acknowledgments}

None.

\section{Footnote}

Conflicts of Interest: The authors have no conflicts of interest to declare.

Ethical Statement: The authors are accountable for all aspects of the work in ensuring that questions related to the accuracy or integrity of any part of the work are appropriately investigated and resolved. The study protocol was approved by the Sejong General Hospital Institutional Review Board (IRB No. 2018-0811, approval date 12-122018).

\section{References}

1. Ruka E, Dagenais F, Mohammadi S, et al. Bilateral mammary artery grafting increases postoperative mediastinitis without survival benefit in obese patients. Eur J Cardiothorac Surg 2016;50:1188-95.

2. Leaper DJ. Traumatic and surgical wounds. BMJ 2006;332:532-5.

3. Guo S, Dipietro LA. Factors affecting wound healing. J Dent Res 2010;89:219-29.

4. Kuroki LM, Mullen MM, Massad LS, et al. Wound complication rates after staples or suture for midline vertical skin closure in obese women: a randomized controlled trial. Obstet Gynecol 2017;130:91-9.

5. Al-Mubarak L, Al-Haddab M. Cutaneous wound closure materials: an overview and update. J Cutan Aesthet Surg 2013;6:178-88. 
6. Levi K, Ichiryu K, Kefel P, et al. Mechanics of wound closure: emerging tape-based wound closure technology vs. traditional methods. Cureus 2016;8:e827.

7. Mangram AJ, Horan TC, Pearson ML, et al. Guideline for prevention of surgical site infection, 1999. Centers for Disease Control and Prevention (CDC) Hospital Infection Control Practices Advisory Committee. Am J Infect Control 1999;27:97-132; quiz 133-4; discussion 96.

8. Peterson MD, Borger MA, Rao V, et al. Skeletonization of bilateral internal thoracic artery grafts lowers the risk of sternal infection in patients with diabetes. J Thorac Cardiovasc Surg 2003;126:1314-9.

9. Sá MP, Cavalcanti PE, de Andrade Costa Santos HJ, et al. Skeletonized versus pedicled bilateral internal mammary artery grafting: outcomes and concerns analyzed through a meta-analytical approach. Int J Surg 2015;16:146-52.

10. Taggart DP, Altman DG, Gray AM, et al. Randomized trial of bilateral versus single internal-thoracic-artery grafts. N Engl J Med 2016;375:2540-9.

11. Saito A, Miyata H, Motomura N, et al. Propensitymatched analysis of bilateral internal mammary artery vs

Cite this article as: Lee H, Yeom SY, Kim HJ, Yoo JS, Kim DJ, Cho KR. Comparison between noninvasive and conventional skin closure methods in off-pump coronary artery bypass grafting using bilateral internal thoracic artery. J Thorac Dis 2019;11(9):3920-3928. doi: 10.21037/jtd.2019.08.87 single internal mammary artery in 7702 cases of isolated coronary artery bypass grafting. Eur J Cardiothorac Surg 2013;44:711-7.

12. De Maria E. New skin closure system facilitates wound healing after cardiovascular implantable electronic device surgery. World J Clin Cases 2015;3:675-7.

13. Carli AV, Spiro S, Barlow BT, et al. Using a non-invasive secure skin closure following total knee arthroplasty leads to fewer wound complications and no patient home care visits compared to surgical staples. Knee 2017;24:1221-6.

14. Tanaka Y, Miyamoto T, Naito Y, et al. Randomized study of a new noninvasive skin closure device for use after congenital heart operations. Ann Thorac Surg 2016;102:1368-74.

15. Maroz N, Simman R. Wound healing in patients with impaired kidney function. J Am Coll Clin Wound Spec 2014;5:2-7.

16. Gatti G, Perrotti A, Reichart D, et al. Glycated hemoglobin and risk of sternal wound infection after isolated coronary surgery. Circ J 2016;81:36-43. 